\title{
Mechanistic properties of the unaged and aged DGAMs
}

\author{
Al-Hadidy A.I. \\ Lecturer of Civil Engineering Department, \\ University of Mosul, Mosul/Iraq, \\ E-mail address abd_et76@yahoo.com. \\ Tel. +9647710736289
}

\author{
Rashed Abdullah M. \\ MSc. Student, Civil Engineering Department \\ University of Mosul, Mosul/Iraq
}

\begin{abstract}
Short and long term aging were conducted on the dense graded asphalt mixtures (DGAMs) containing 40-50 penetration grade asphalt cement binders. The short term oven aging (STOA) was conducted on loose mixtures at temperature of $135{ }^{\circ} \mathrm{C}$ for four hours and at temperature of $154^{\circ} \mathrm{C}$ for two hours, whereas, the long term oven aging (LTOA) was conducted at temperature of $85^{\circ} \mathrm{C}$ and at two periods of time between four and eight days. The performance tests includes: Marshall properties, indirect tensile strength at 25 and $60^{\circ} \mathrm{C}$, compressive strength at 25 and $60^{\circ} \mathrm{C}$, flexural strength at 0 and $-10^{\circ} \mathrm{C}$, cohesion at $60^{\circ} \mathrm{C}$, tensile strength ratio, and index of retained strength were carried out on unaged and aged DGAM. A mechanistic-empirical design approach using BISAR program was adopted for estimating the improvement in service life of the pavement or reduction in thickness of DGAM and base layer for the same service life due to the aging of DGAM. The results showed that the STOA and LTOA increases: (1) resistance of DGAM against permanent deformation at high temperatures; (2) resistance to stripping phenomenon; (3) flexural strength at low temperatures; (4) traffic benefit ratio between 10 and $20 \%$; and (5) reduces the thickness of the surface layer between 8 and $14 \%$; and (6) the base thickness reduces between $35 \%$ and $55 \%$.

Keywords: Aging, Asphalt binders, Performance tests, Service life, Pavement response.
\end{abstract}

\section{الخصائص الميكانيكية للخلطات الإسفلتية الكثيفة غير المعرضة والمعرضة للتقادم}

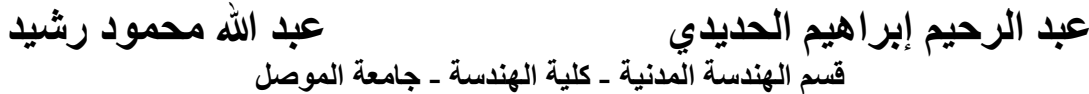

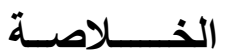

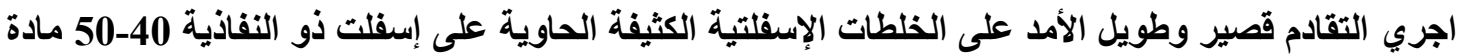

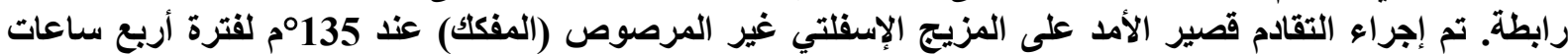

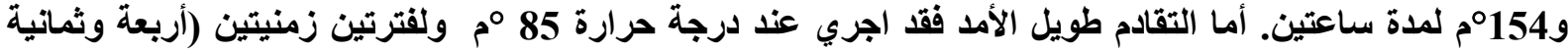

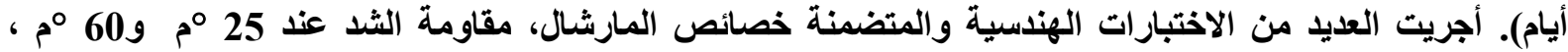

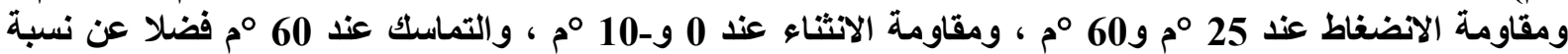

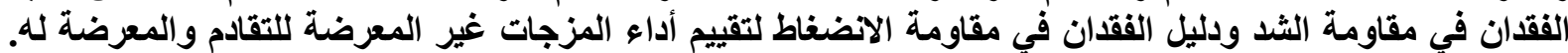

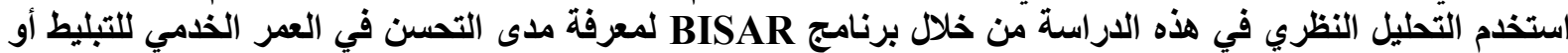

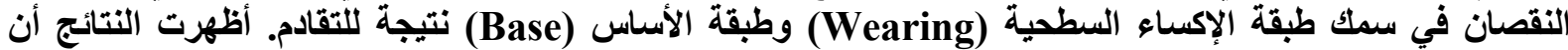

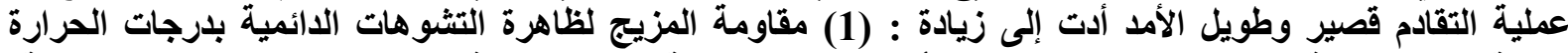

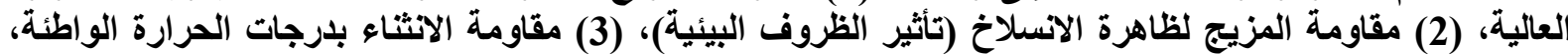

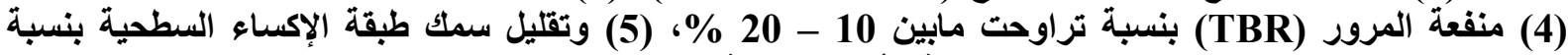

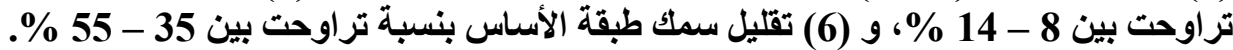
مفاتيح الكلمات: التقادم ، الاسفلت الرابط ، اختبارات الاداء ، سنوات الخدة الخدمة، اجهادادات التبليط. 


\section{Introduction}

The progressive oxidation (aging) of the asphalt concrete (AC) mixture and water content of the base and subgrade are two of the most important environmental factors that influence flexible pavement performance. Aging affects the stiffness of the asphalt-bound layers, which alters the stress state throughout the pavement. This change in stress state can, in turn, affect the stiffness of the underlying unbound layers since they usually exhibit stress dependence. The structural capacity of the entire pavement system is thus affected by changes in pavement temperature.

Likewise, moisture content changes in the base and subgrade affect the stiffness of those pavement system components but may also cause increased strains in the AC layer by reducing the support available.

Mechanistic-empirical pavement design methods for flexible pavements often assume two competing failure mechanisms related to the design of the pavement cross section: fatigue of bound pavement layers and accumulated permanent deformations in the subgrade. Based on observations that the number of load repetitions needed to fail an asphalt concrete beam in flexure is inversely related to the tensile strains at the bottom of the beam, the expected life of a pavement should be inversely related to the traffic-induced tensile strains at the bottom of the asphalt-bound pavement layers. Observations that cyclically loaded soil specimens accumulate plastic (non-recoverable) strains with each loading cycle suggest that the expected life of a pavement should also be inversely related to the traffic-induced compressive strains at the top of the subgrade. The traffic-induced strains in the pavement and subgrade are substantially affected by the stiffness of the asphalt-bound layers, which affects the stress distribution throughout the pavement.

Many studies have been conducted evaluating the aging effects on asphalt binders since their properties can be easily measured using many conventional tests, such as rotational viscometer, dynamic shear rheometer (DSR), and bending beam rheometer (BBR). However, studies on asphalt mixture aging have been limited to mechanical properties such as strength and fatigue characteristics because considerable effort is required to identify the aging of the asphalt binder in a mixture.

Soon-Jae Lee et.al. [1] evaluated the effects of short-term oven aging (STOA) on asphalt mixtures using the gel-permeation chromatography (GPC) procedure. Nine asphalt mixtures, using three different binder sources, were prepared and five short-term aging methods were used to evaluate these mixes. For comparison, the RTFO aging was also conducted for nine asphalt binders. The aging of a binder within asphalt mixtures, including polymer-modified mixtures, could be identified under various STOA conditions. Statistical analysis of the GPC test results indicated that two commonly used STOA methods in the laboratory, a $154{ }^{\circ} \mathrm{C}$ oven aging for $2 \mathrm{~h}$ and a $135^{\circ} \mathrm{C}$ oven aging for $4 \mathrm{~h}$, are not significantly different, based on the increase in the large molecular size (LMS) ratios. The RTFO aging method was found to have less effect on binder aging than the short-term oven aging methods of asphalt mixtures.

Al-Hadidy and Tan [2] investigated the influence of accelerated weathering (aging) on the engineering properties of modified asphalt mixtures with pyrolysis polypropylene (PP). The accelerated weathering was done at a temperature of $85^{\circ} \mathrm{C}$ and over two periods of time, namely between two and four days. The results showed that variations in age change the physical properties of modified mixtures.

Soon-Jae Lee et.al. [3] compared the aging effects of the RTFOT and the STOA methods using the GPC and selected Superpave binder tests. For this study, nine asphalt binders were prepared, and five aging periods were used the RTFOT and four aging treatments were selected for the STOA. Loose asphalt mixes were obtained from six field projects. The results of GPC test showed that the RTFOT method has less aging effect on the binders than the STOA methods for asphalt mixtures prepared in the laboratory. The longer the aging time in 
the RTFOT led to an increase in the high temperature viscosity and the failure temperature of asphalt binders, the only exception being the rubber-modified binders. The GPC was effective in evaluating the aging effect of rubber-modified binders using different RTFOT aging times.

\section{OBJECTIVES OF THE PRESENT STUDY}

The objectives of the present study are: (1) To determine Marshall properties of unaged and aged dense graded asphalt mixtures (DGAMs); (2) To determine static indirect tensile strength of unaged and aged DGAMs at 25 and $60^{\circ} \mathrm{C}$; (3) To determine static compressive strength of unaged and aged DGAMs at 25 and $60 \mathrm{oC}$; (4) To evaluate moisture susceptibility of aged DGAMs and compare with unaged DGAMs; (5) To determine flexural strength properties of unaged and aged DGAMs at different low temperatures; (6) To determine the cohesion of unaged and aged DGAMs at $60^{\circ} \mathrm{C}$; (7) To determine the aging index of unaged and aged DGAMs; (8) To optimize the STOA and long term-Oven aging (LTOA) conditions for any field applications.; (9) Establish regression equations between the performance measures (Marshall stability, indirect tensile strength, and compressive strength) for situations in which: a) the indirect tensile and compressive strength tests were not available, and /or b) the designer does not choose to use those tests, and (10) Evaluation the benefits of aged DGAM layer in flexible pavement using a mechanistic-empirical design approach. Meeting these objectives could provide a better understanding of the effects of aging on the physical and engineering properties of DGAMs so that their performance in the field can be more accurately predicted.

\section{EXPERIMENT}

\section{Materials}

40-50 penetration grade asphalt taken form Qayarah (Q) refinery $(30 \mathrm{Km}$. South of Mosul city) was selected for this study. Some properties of this asphalt are listed in Table 1. Asphalt has asphaltene content $(6.7 \%)$.

Aggregate was obtained from one asphalt plant in Mosul city located in the north part of Iraq. Figure 1 shows the recommended gradation limits by the ASTM (D3515) for dense graded asphalt mixtures (DGAMs) and the selected gradation in this research was in the middle of the limits. The properties of the aggregates, such as angularity value, toughness value, soundness value, and specific gravities were determined, and the test results are presented in Table 2.

Calcium carbonate $\left(\mathrm{CaCo}_{3}\right)$ was used as mineral filler. It was passed through a 200 sieve and had specific gravity of 2.731 by ASTM designation D854 [4].

Table 1 Physiochemical properties of asphalt cement

\begin{tabular}{cccc}
\hline Property & Result & ASTM limits & SCRB limits \\
\hline Penetration $\left(25^{\circ} \mathrm{C}, 100 \mathrm{~g}, \mathrm{dmm}\right)$ & 41 & $40-50$ & $40-50$ \\
\hline Softening point, ${ }^{\circ} \mathrm{C}$ & 52 & $50-58$ & $51-62$ \\
\hline Ductility $\left(25^{\circ} \mathrm{C}, \mathrm{cm}\right)$ & $100^{+}$ & $100 \mathrm{~min}$ & $100 \mathrm{~min}$ \\
\hline Specific gravity & 1.049 & $1.01-1.06$ & --- \\
\hline Flash point, ${ }^{\circ} \mathrm{C}$ & 263 & $240 \mathrm{~min}$ & $240 \mathrm{~min}$ \\
\hline Loss of heat and air, $\%$ & 0.386 & $0.2 \mathrm{max}$ & $0.75 \mathrm{max}$ \\
\hline Kinematic viscosity $@, 135^{\circ} \mathrm{C} .(\mathrm{CSt})$ & 500 & $400 \mathrm{~min}$ & ---- \\
\hline \%Sulfur $\left(\mathrm{S}_{3}\right)(\mathrm{X}-\mathrm{Ray})$ & 7.6 & & $6.5 \%[5]$ \\
\hline Ashaltene, $\%$ & 6.7 & --- & --- \\
\hline Solubility, $\%$ & 99.7 & $99 \mathrm{~min}$ & $99 \mathrm{~min}$ \\
\hline Residue ductility $\left(25^{\circ} \mathrm{C}, \mathrm{cm}\right)$ & 97 & --- & $50 \mathrm{~min}$ \\
\hline Residue penetration, $\%$ of original & 68 & --- & $55 \mathrm{~min}$ \\
\hline Increase of softening point after TFOT, ${ }^{\circ} \mathrm{C}$ & 4 & --- & $10 \mathrm{max}$ \\
\hline
\end{tabular}




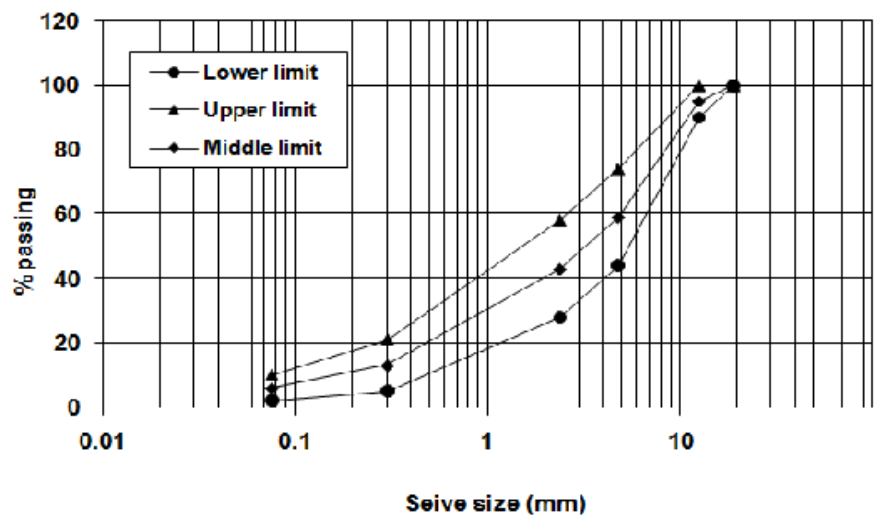

Fig. 1 gradation limits.

Table 2 Source and consensus properties of aggregate

\begin{tabular}{|c|c|c|}
\hline Property & Coarse Aggregate & Fine Aggregate \\
\hline Bulk sp.gr. & 2.652 & 2.541 \\
\hline Apparent sp.gr. & 2.693 & 2.592 \\
\hline Angularity,\% & 99 & 47.00 \\
\hline Toughness, $\%$ & 19 & ----- \\
\hline Soundness, $\%, \mathrm{Na}_{2} \mathrm{SO}_{4}$ & 0.968 & 0.664 \\
\hline
\end{tabular}

\section{Mixture design}

The optimum asphalt content for DGAMs is usually selected to produce $3-5 \%$ air voids. Five asphalt percentages $(4.0 \%, 4.5 \%, 5.0 \%, 5.5 \%$ and $6.0 \%)$ were used in the design of the DGAMs. It was found that at $4.0 \%$ air voids, the required asphalt content was $5.0 \%$. This optimum asphalt content was used in preparing all other aged mixtures to maintain consistency through the study.

Then five groups of samples are mixed at this ratio of asphalt and at the appropriate mixing temperature of $150{ }^{\circ} \mathrm{C}$ to $160{ }^{\circ} \mathrm{C}$ by mechanical mixer for 2 minutes [6]. The first group was labeled as unaged $\left(\mathrm{DGAM}_{0 \mathrm{~h}}\right)$. The second group was then aged by placing the loose mix in a flat pan and into a Forced Draft Oven (Figure 2) at $135{ }^{\circ} \mathrm{C}$ for four hours and labeled as $\left(\right.$ DGAM $\left._{4 h}\right)$. The third group was aged by placing the loose mix in a flat pan and into a Forced Draft Oven at $154{ }^{\circ} \mathrm{C}$ for two hours and labeled as $\left(\mathrm{DGAM}_{2 \mathrm{~h}}\right)$. The fourth group was aged by placing the compacted samples into a Forced Draft Oven at $85^{\circ} \mathrm{C}$ for 4 days and labeled as $\left(\right.$ DGAM $\left._{4 d}\right)$. The fifth group was aged by placing the compacted samples into a Forced Draft Oven at $85^{\circ} \mathrm{C}$ for 8 days and labeled as $\left(\right.$ DGAM $\left._{8 \mathrm{~d}}\right)$. These conditions followed aging procedures described in $[1,7,8$,

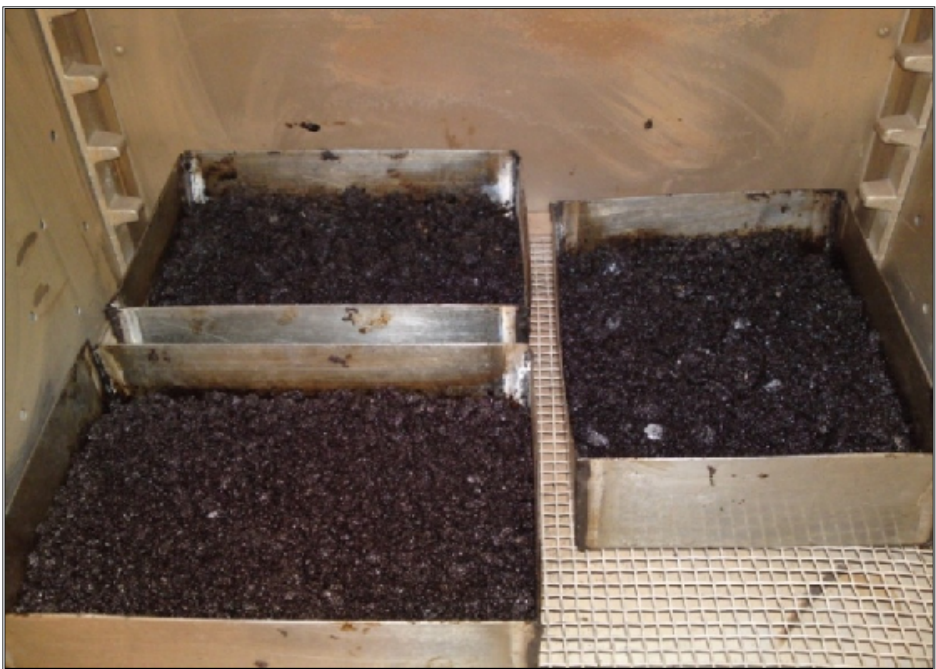

Fig. 2 loose mix in a flat pan placed into a Forced Draft Oven and 9]. 
The loose samples were then brought to compaction temperature equivalent to viscosity of $(280 \pm 30 \mathrm{Cst})[6]$. A Marshall mechanical compactor was used to consolidate the hot mixtures. The specimens were compacted for heavy-duty of 75 Marshall blows for each face as a tire pressure of $1379 \mathrm{kPa}$. The specimens were then removed from the mold [4], and left to cure in air for $24 \mathrm{~h}$. Twenty-six specimens for each group of unaged and aged DGAMs were tested with three for Marshall stability at $60{ }^{\circ} \mathrm{C}$, three for cohesion at $60{ }^{\circ} \mathrm{C}$, three for indirect tensile strength (ITS) at $25^{\circ} \mathrm{C}$, three for ITS at $60{ }^{\circ} \mathrm{C}$, three for compressive strength (CS) at $25{ }^{\circ} \mathrm{C}$, three for $\mathrm{CS}$ at $60^{\circ} \mathrm{C}$, four for flexural strength (FS) at $0{ }^{\circ} \mathrm{C}$, and four for $\mathrm{FS}$ at $10^{\circ} \mathrm{C}$. Thus, one-hundred and thirty samples were tested for all groups.

\section{Laboratory tests used}

Four tests in the laboratory were adopted. The tests performed were Marshall stability, ITS at 25 and $60^{\circ} \mathrm{C}, \mathrm{CS}$ at 25 and $60^{\circ} \mathrm{C}$, flexural strength at 0 and $-10^{\circ} \mathrm{C}$, and cohesion at $60^{\circ} \mathrm{C}$ tests. In addition, the moisture susceptibility test was studied using the tensile strength ratio (TSR) and index of retained strength (IRS) according to ASTM D-4123 and D-1074 [4], respectively. A TSR and IRS of wet group to dry group were computed from the results of the ITS and CS tests at $25^{\circ} \mathrm{C}$. The higher the TSR or IRS value, the less the strength should be influenced by the water soaking condition, or the more water-resistant it should be. DGAMs specification according to SCRB [10] requires IRS values of $70 \%$ or more, whereas, SCDOT [11] requires a TSR and wet tensile strength values of $85 \%$ or more and $448 \mathrm{kPa}$, respectively. Aging index (A.I.) was also determined from the cohesion values obtained for aged and unaged DGAMs.

Rutting resistance was evaluated by Marshall Quotient (MQ). Flexural test was done on small beams of the dimension $300 \times 50 \times 48 \mathrm{~mm}$ cutting from a compacted square slab specimen $(30 \times 30 \times 5 \mathrm{~cm})$. Four series of beam specimens were prepared and tested at 0 and $10^{\circ} \mathrm{C}$ temperatures using a universal testing machine and temperature control cabinet. This was to monitor the low temperature behavior of DGAMs.

Elastic modulus $\left(E_{C}\right)$ is one of the most important mechanical properties of asphalt concrete. When elastic-layered system theory is used to design asphalt pavement structures, the modulus of asphalt concrete is a basic design parameter. The current asphalt pavement performance predicted models also use the modulus as a critical material parameter. Therefore, it is desirable that the modulus of asphalt concrete be predicted during the asphalt concrete mixture design stage to improve mixture design and pavement performance prediction. The modulus of elasticity (Ec) at $25^{\circ} \mathrm{C}$ was determined using equation (1) mentioned by Tan and Al-Hadidy [2].

$$
\mathrm{Ec}=483 \times \mathrm{Ms} \quad\left(\mathrm{Ib} / \mathrm{in}^{2}\right)
$$

Where

$\mathrm{Ms}=$ Marshall stability in $\mathrm{kg}$ at $60^{\circ} \mathrm{C}$.

\section{Mechanistic empirical design}

A mechanistic-empirical (M-E) design approach has been used in the present study to evaluate the benefits of aging the DGAMs in terms of reduction in layer thickness and extension in service life of the pavement. The proposed methodology has a better capability of characterizing different material properties and loading conditions, and has the ability to evaluate different design alternatives on an economic basis. 
Two design alternatives considered in the present study are as follows:

1. The same service life for the aged and unaged pavement sections. It would lead to reduction in base, or DGAM thickness and has been expressed in terms of Layer Thickness Reduction (LTR); and

2. The same pavement sections for unaged and aged DGAM. It would result in more service life of the pavement due to the aging and has been expressed in terms of Traffic Benefit Ratio (TBR).

As input values, DGAM modulus was determined, and typical moduli of asphalt, base, subbase and subgrade in Iraq were selected as shown in Figure 3.

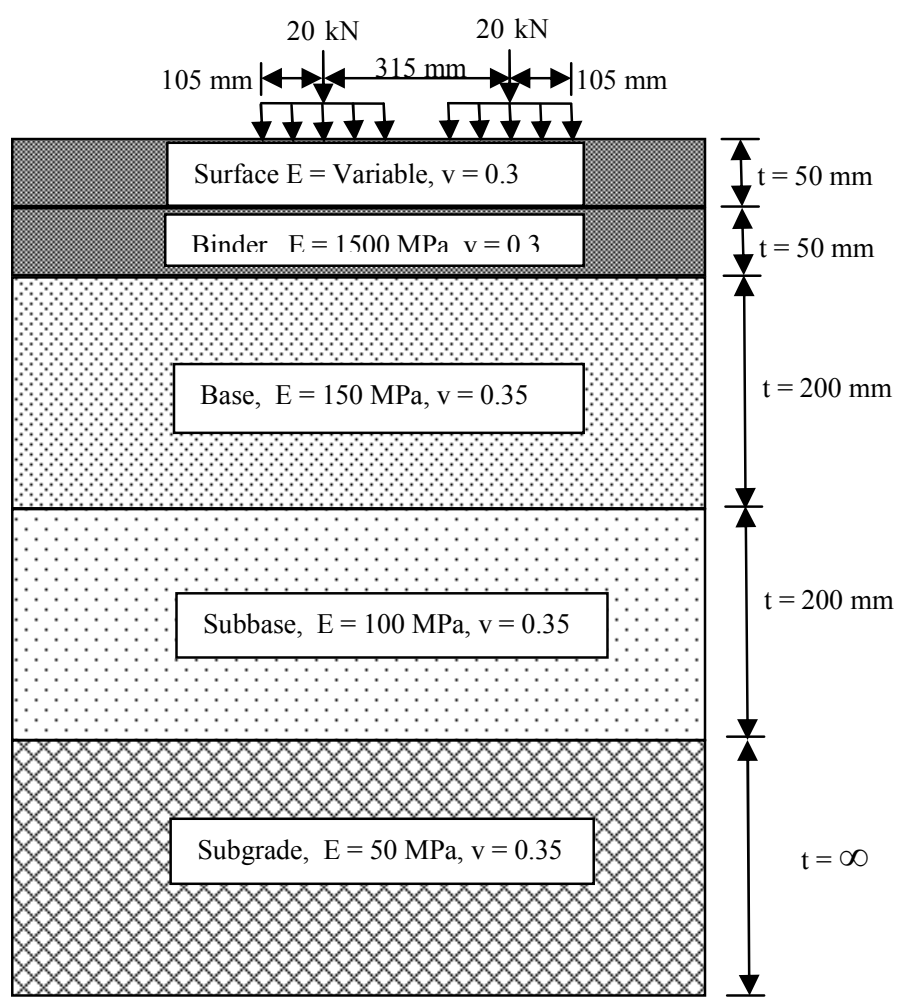

Fig. 3 Pavement design and considered loading: dual tires

The surface deflection $\left(\mathrm{w}_{\mathrm{o}}\right)$, the horizontal tensile strain at the bottom of binder layer $\left(\varepsilon_{\mathrm{t}}\right)$ and the vertical compressive strain at the top of subgrade layer $\left(\varepsilon_{\mathrm{c}}\right)$ were calculated under the left tire using multi-layer elastic analysis program, BISAR using $40 \mathrm{kN}$ set of dual tires with $105 \mathrm{~mm}$ radius. These responses were used for estimating the improvement in service life of the pavement or reduction in thickness of DGAM and base layer for the same service life due to aging of DGAM.

\section{RESULTS AND DISCUSSION}

\section{Statistical considerations}

Results of the Marshall, indirect tensile strength, compressive strength, tensile strength ratio, index of retained strength, flexural strength, and cohesion tests were statistically analyzed with a 5\% level of significance. For these comparisons, it should be noted that all specimens were produced at optimum asphalt content. 


\section{Linear regression analysis}

The change in the engineering properties with aging conditions of DGAMs was studied at high and intermediate pavement temperatures. Statistical analysis including Pearson coefficient of correlation (R) and significant (2-tailed, $\mathrm{p}$ ) was used to verified that a linear relationship has enough accuracy for determination Marshall stability, indirect tensile and compressive strength properties of DGAMs for STOA and LTOA.

Figure 4 show the linear relationships between the performance tests and summarizes the linear regression of DGAMs for both aging; STOA and LTOA performed at $5 \%$ significant level. The results are average of all laboratory mixtures tested at temperatures of 25 and $60^{\circ} \mathrm{C}$. The analysis verified that linear relationships could be used for determination of indirect tensile and compressive strength properties of DGAMs at temperatures of 25 and $60^{\circ} \mathrm{C}$. These equations were developed for situations in which: a) the indirect tensile and/or compressive strength tests were not available, and /or b) the designer does not choose to use those tests.
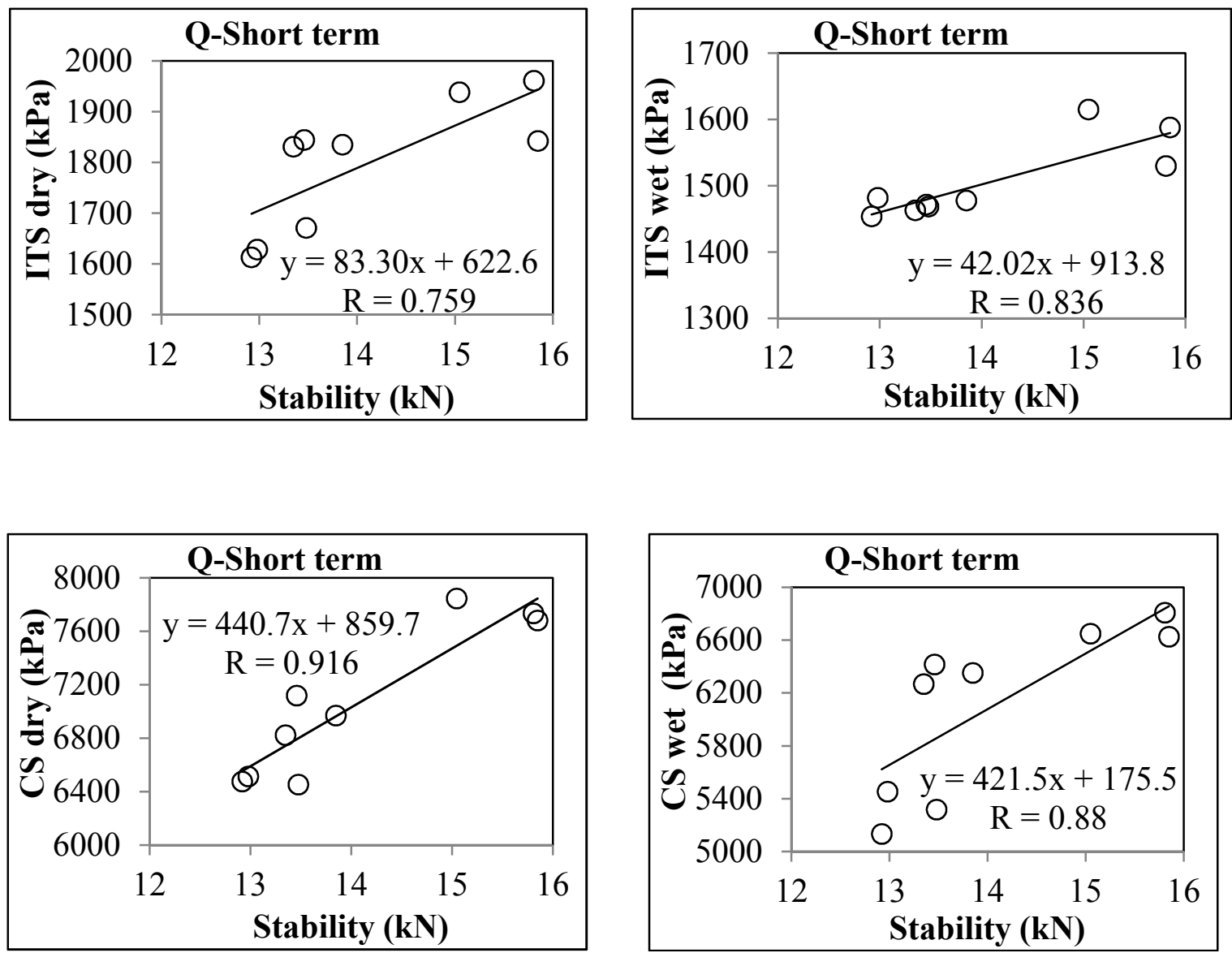

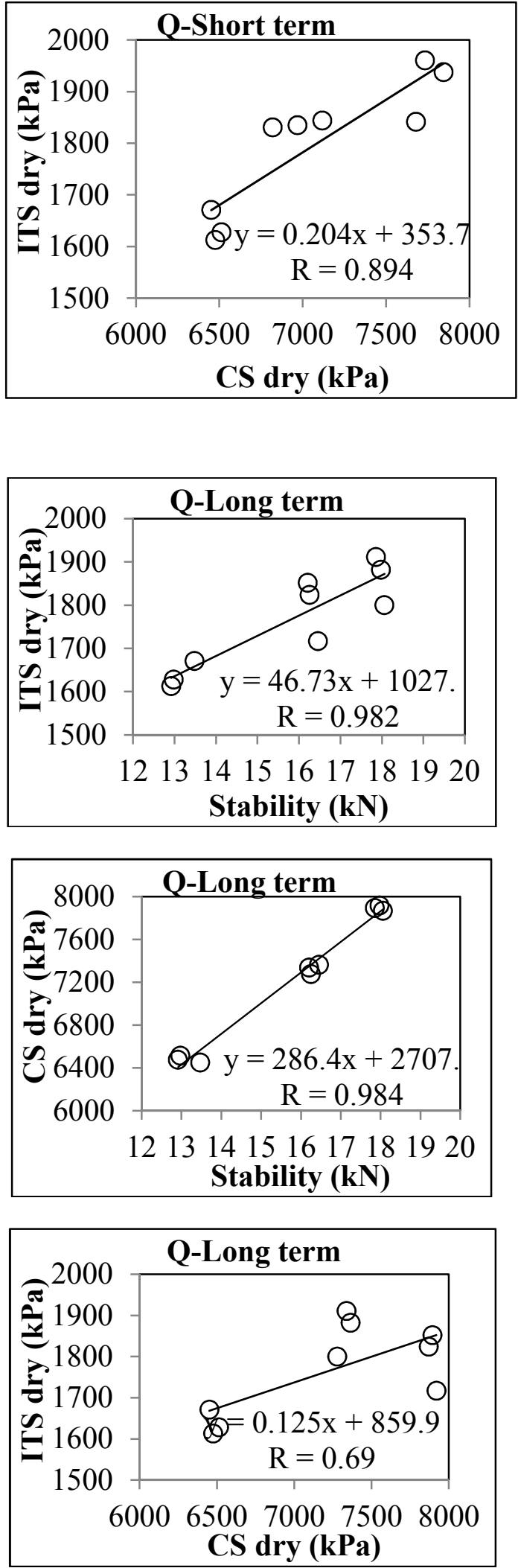

(b)

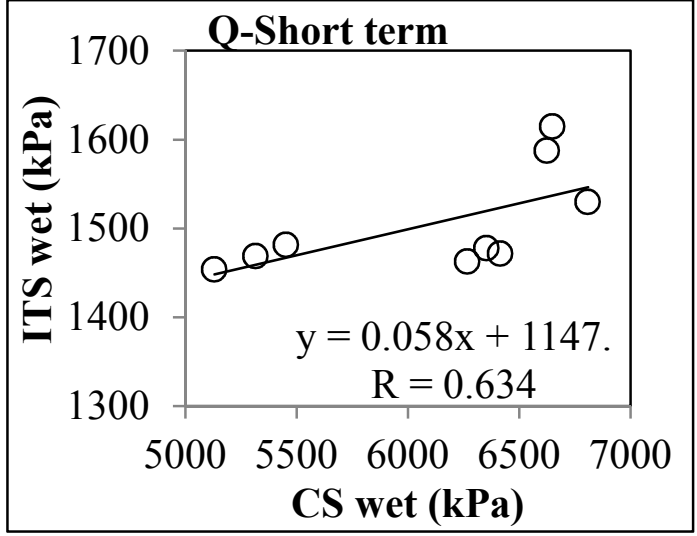

(a)
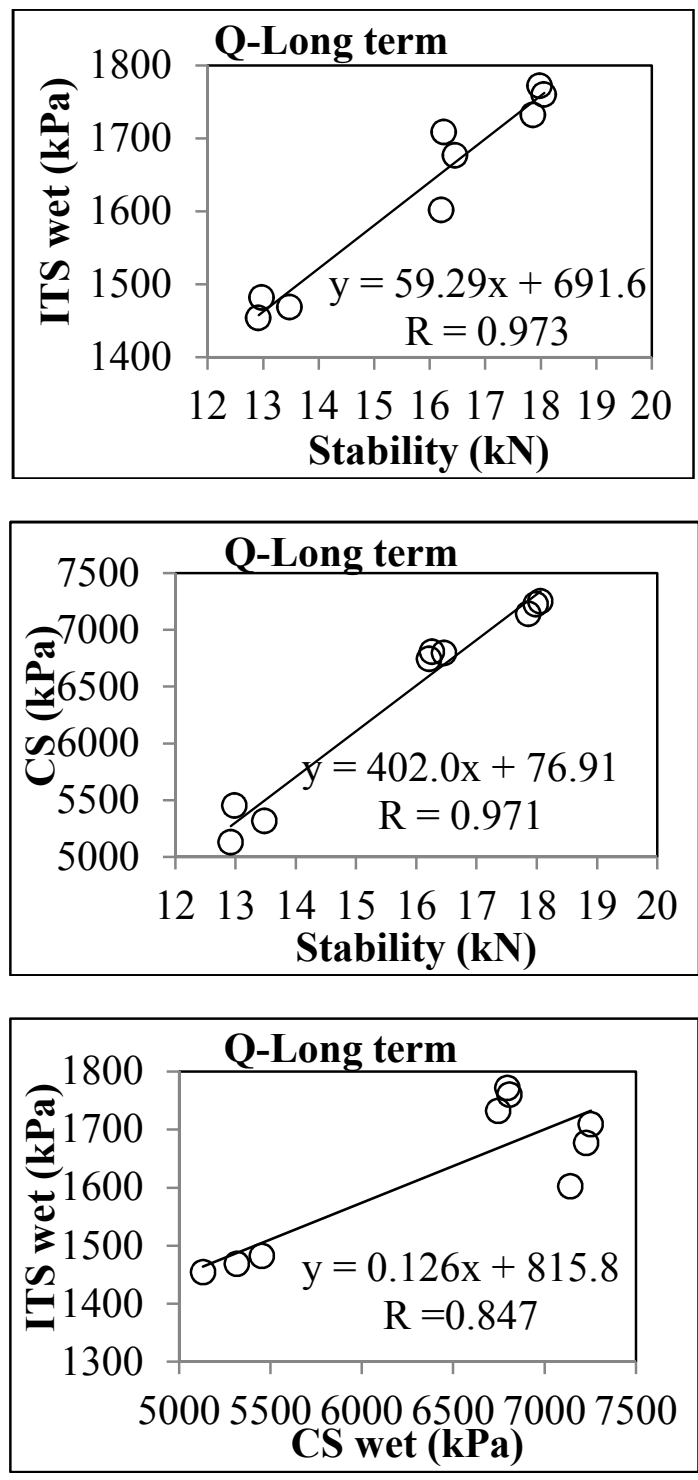

Fig. 4 Relationships between the performance measures of DGAMs and summary of $R$ (a-STOA and b-LTOA) 


\section{Optimization of DGAMs}

SPSS statistical analysis program V.16 was used to prepare an optimization Table based on the performance measures conducted on DGAMs. Duncan correlation [12] was selected to determine the significant between groups. This significant was defined by addition a letter(s) for each group. If the letter(s) shared between two groups or more, this indicates that no significant can be found between groups. Results obtained from such analysis are summarized in Table 3 can be used to select the aging conditions for any field applications. Actual selecting would depend upon the option exercised by the designer.

Table 3 Optimization of unaged and aged DGAMs

\begin{tabular}{l|c|c|c|c|c}
\hline Mixture type & DGAM $_{0 \mathrm{~h}}$ & DGAM $_{2 \mathrm{~h}}$ & DGAM $_{4 \mathrm{~h}}$ & DGAM $_{4 \mathrm{~d}}$ & DGAM $_{8 \mathrm{~d}}$ \\
\hline $\mathrm{MS}, \mathrm{kN}$ & $13.13 \pm 0.35$ & $15.57 \pm 0.51$ & $13.55 \pm 0.47$ & $17.79 \pm 0.11$ & $16.31 \pm 0.23$ \\
\hline $\mathrm{TS} 1, \mathrm{kPa}$ & $1637 \pm 34$ & $1914 \pm 71$ & $1837 \pm 75$ & $1864 \pm 65$ & $1798 \pm 81$ \\
\hline $\mathrm{TS} 2, \mathrm{kPa}$ & $1648 \pm 16$ & $1578 \pm 49$ & $1471 \pm 8.5$ & $1755 \pm 23$ & $1663 \pm 62$ \\
\hline $\mathrm{SC}_{1}, \mathrm{kPa}$ & $6480 \pm 35$ & $7758 \pm 87$ & $6969 \pm 167$ & $7327 \pm 51$ & $7894 \pm 28$ \\
\hline $\mathrm{SC}_{2}, \mathrm{kPa}$ & $5300 \pm 182$ & $6693 \pm 113$ & $6344 \pm 83$ & $6748 \pm 37$ & $7208 \pm 66$ \\
\hline $\mathrm{MF}, \mathrm{kPa}, 0{ }^{\circ} \mathrm{C}$ & $5160 \pm 99$ & $6370 \pm 79$ & $5284 \pm 108$ & $6523 \pm 114$ & $6393 \pm 121$ \\
\hline $\mathrm{MF}, \mathrm{kPa},-10^{\circ} \mathrm{C}$ & $5642 \pm 175$ & $6810 \pm 139$ & $5707 \pm 119$ & $6997 \pm 158$ & $6804 \pm 137$ \\
\hline
\end{tabular}

Means with different letters vertically have significant difference at $\mathrm{p} \leq 0.05$, MS =Marshall stability; $\mathrm{SC}_{1}=$ Compressive strength at $25^{\circ} \mathrm{C} ; \mathrm{SC}_{2}=$ Compressive strength at $60^{\circ} \mathrm{C} ; \mathrm{TS}_{1}=$ Tensile strength at $25^{\circ} \mathrm{C}$; $\mathrm{TS}_{2}=$ Tensile strength at $60^{\circ} \mathrm{C} ; \mathrm{MF}=$ Flexural modulus;

\section{Marshall properties}

The Marshall properties of unaged and aged DGAMs were evaluated and the results are presented in Figures 5, respectively. From these Figures, it can be seen that the aging period of $2 \mathrm{~h}, 4 \mathrm{~h}, 4 \mathrm{~d}$, and $8 \mathrm{~d}$ raises the Marshall stability of control (unaged) DGAM by 19\%, 3\%, $37 \%$ and $24 \%$, respectively, whereas flow value for these aging periods decreases by $24 \%$, $12 \%, 35 \%$, and $30 \%$, respectively.

The sited results in Figures 5 also revealed that the aging period of $2 \mathrm{~h}, 4 \mathrm{~h}, 4 \mathrm{~d}$, and $8 \mathrm{~d}$ raises the voids in mineral aggregates (VMA) by $8 \%, 14 \%, 2 \%$ and $4 \%$, respectively. This indicates that STOA and LTOA increases the durability of DGAMs. In addition, it was found that LTOA satisfies the specified limits of 3-5\% air voids (Av).

From the sited results in Figure 5, it was found that the MQ value of unaged DGMA increased by $56 \%, 17 \%, 111 \%$, and $78 \%$ at $2 \mathrm{~h}, 4 \mathrm{~h}, 4 \mathrm{~d}$, and $8 \mathrm{~d}$ aging periods, respectively. It can be said that the aged DGAMs provide better resistance against permanent deformations due to their high stability and high MQ and indicate that aged DGAMs could be use in military airfield pavements where stiff asphalt mixture and low asphalt content are required. The increase in stability and VMA values may be related to the bonding that happened between $\mathrm{S}=\mathrm{O}, \mathrm{C}=\mathrm{O}$ and $\mathrm{C}-\mathrm{H}$ chain in asphalt cement binder. 
No. 5

Dec. 2014
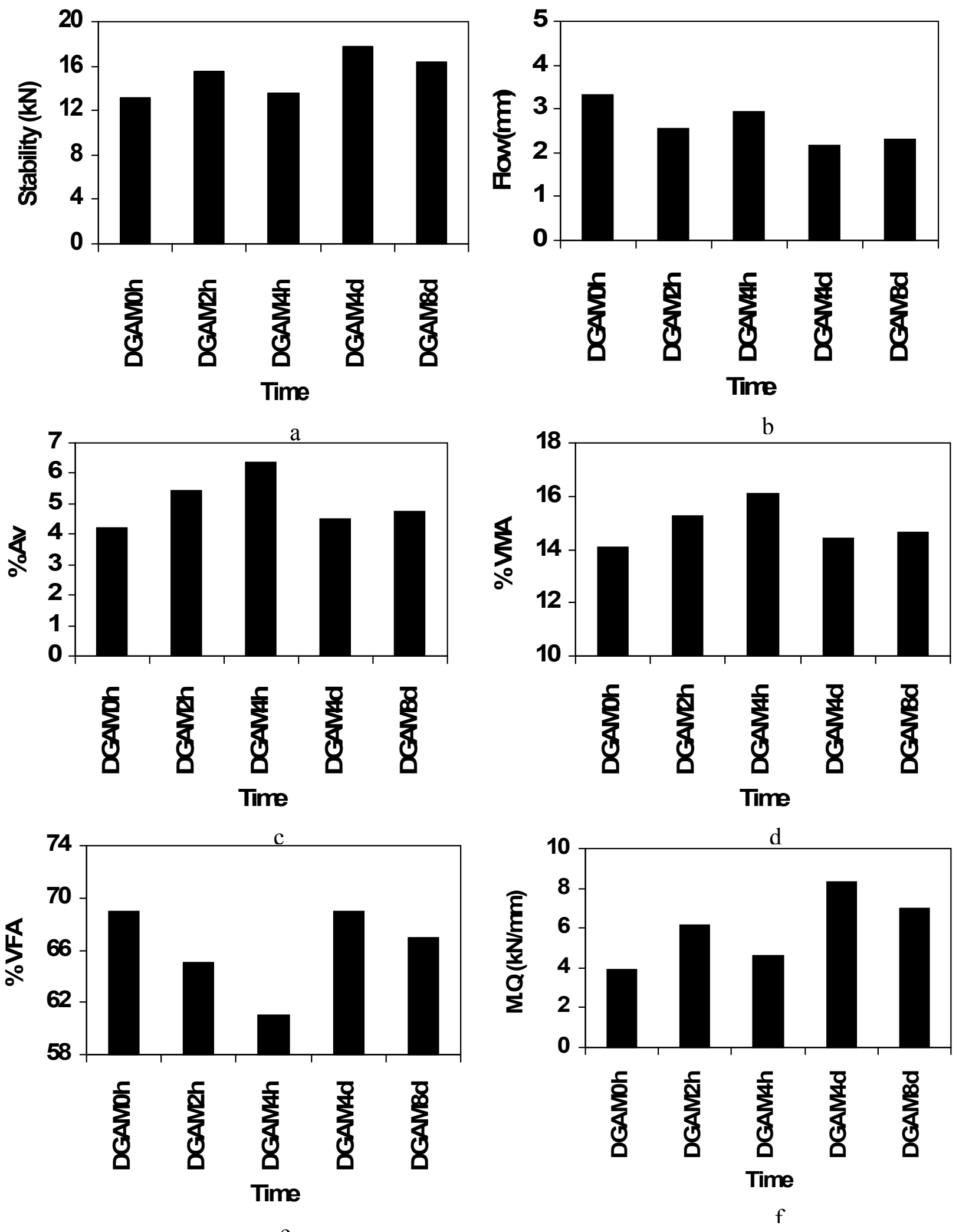

Fig. 5 Marshall properties of DGAMs

(a- stability, b- flow, c- air voids, d- VMA, e- VFB \&, f- MQ)

Moisture susceptibility 
Tensile strength for unaged and aged DGAMs are given in Figures 6. The results indicate that tensile strength, and TSR increased for both STOA and LTOA. For DGAM $0 \mathrm{~h}, \mathrm{DGAM}_{2 \mathrm{~h}}$, DGAM $_{4 \mathrm{~h}}, \mathrm{DGAM}_{4 \mathrm{~d}}$, and DGAM ${ }_{8 \mathrm{~d}}$, average static ITS values of the conditioned DGAM specimens are $1468,1578,1471,1755$, and $1663 \mathrm{kPa}$, respectively. For these, coefficients of variation $(\mathrm{COV})$ of results observed were $0.95,2.71,0.51,1.17$, and $3.3 \%$, respectively. Average static ITS values obtained for unconditioned DGAM specimens are 1637, 1914, 1837,1864 , and $1798 \mathrm{kPa}$, respectively. For these, COV of results observed were 1.84, 3.29, $0.36,3.09$, and $3.96 \%$, respectively. From these, values \% TSR obtained for DGAM $\mathrm{D}_{0 \mathrm{~h}}$,

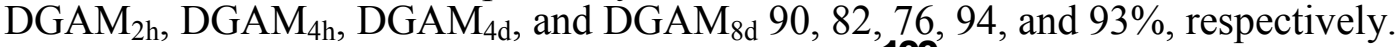

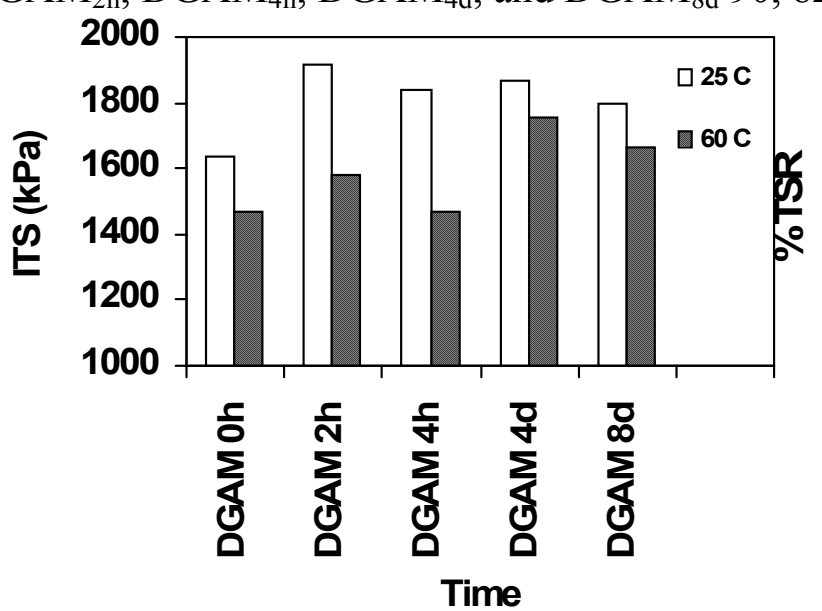

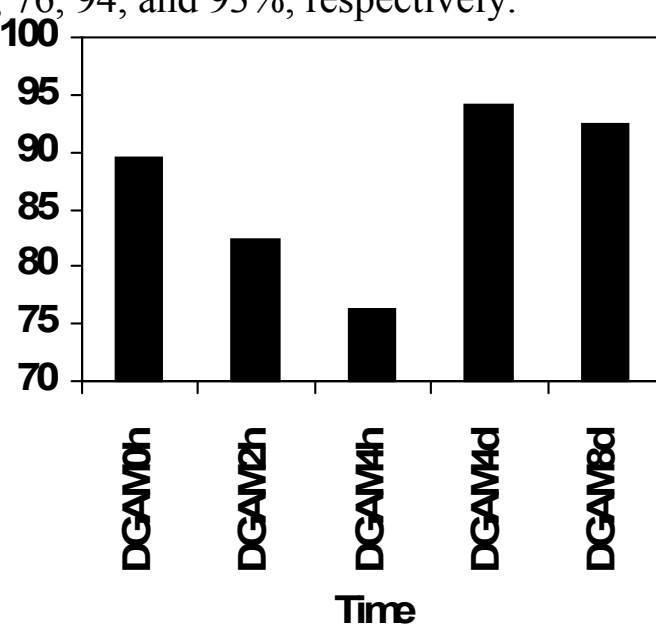

h

Fig. 6 Tensile strength properties of DGAMs

(a. tensile strength $\&$ b. $\%$ TSR).

The variation of the CS with STOA and LTOA is shown in Figures 7, respectively. From these Figures, it can be observed that the ranges of CS for DGAM0h, DGAM2h, DGAM4h, DGAM4d, and DGAM8d samples are 6480 to $5300 \mathrm{kPa}, 7758$ to $6693 \mathrm{kPa}, 6969$ to $6344 \mathrm{kPa}$, 7327 to 6784 , and 7894 to $7208 \mathrm{kPa}$ at 25 and $60^{\circ} \mathrm{C}$, respectively. For these, COV of results observed were 0.48 to $3.0,0.99$ to $1.49,2.12$ to $1.17,0.61$ to 0.48 , and 0.32 to $0.8 \%$, respectively.

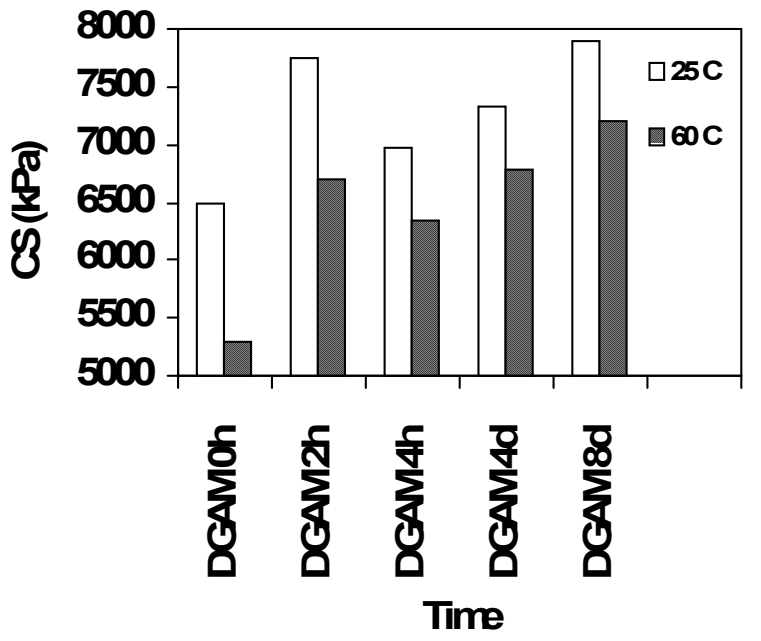

a

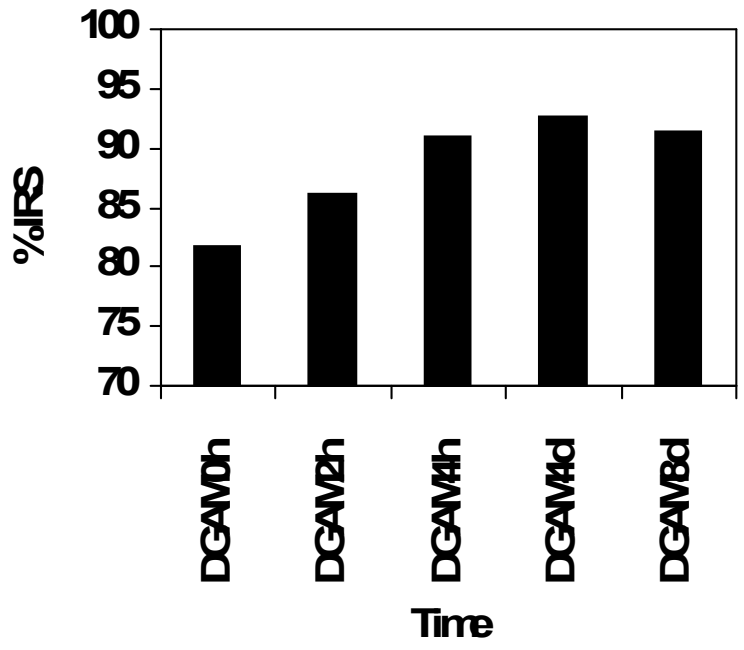

h

Fig. 7 Compressive strength properties of DGAMs

(a. compressive strength \& b. \% IRS) 
The percentage increase in the averaged CS is found to be comparatively significant. The study showed that the percentage increase in CS value for unaged DGAM at $2 \mathrm{~h}, 4 \mathrm{~d}$ and $8 \mathrm{~d}$ aging periods was found to be 20 and $15 \%, 13$ and $17 \%$ and 22 and $24 \%$ at 25 and $60^{\circ} \mathrm{C}$, respectively. From Figure 7, it was found that the IRS of the unaged DGAM was increased by $6 \%, 11 \%, 13 \%$ and $11 \%$ for $\mathrm{DGAM}_{2 \mathrm{~h}}, \mathrm{DGAM}_{4 \mathrm{~h}}, \mathrm{DGAM}_{4 \mathrm{~d}}$, and $\mathrm{DGAM}_{8 \mathrm{~d}}$, respectively. In addition, the observations and the analysis of the results using a statistical program show that the ITS test was the most promising of stripping when applied to airfield and highway paving mixtures.

\section{Elastic modulus}

$E_{C}$ is the most important variable to mechanistic design approaches for pavement structures. It is the measure of pavement response in terms of dynamic stresses and corresponding strains. The modulus of elasticity $(\mathrm{Ec})$ at $25^{\circ} \mathrm{C}$ was determined using equation (1) mentioned by Tan and Al-Hadidy [2] as mentioned earlier.

STOA and LTOA DGAMs showed higher EC values than unaged DGAMs as shown in Figure 8. Test results indicate that EC for $\mathrm{DGAM}_{0 \mathrm{~h}}, \mathrm{DGAM}_{2 \mathrm{~h}}, \mathrm{DGAM}_{4 \mathrm{~h}}, \mathrm{DGAM}_{4 \mathrm{~d}}$, and $\mathrm{DGAM}_{8 \mathrm{~d}}$ samples are $4460 \mathrm{MPa}, 5260 \mathrm{MPa}, 4600 \mathrm{MPa}, 6100 \mathrm{MPa}$, and $5540 \mathrm{MPa}$ at $25^{\circ} \mathrm{C}$, respectively, the Ec increases by $18 \%, 37 \%$ and $24 \%$ for $2 \mathrm{~h}, 4 \mathrm{~d}$, and $8 \mathrm{~d}$ aging periods, respectively. Therefore, aging has improved the Ec of DGAMs. This might be attributed to the higher the viscosity of aged asphalt mixes.

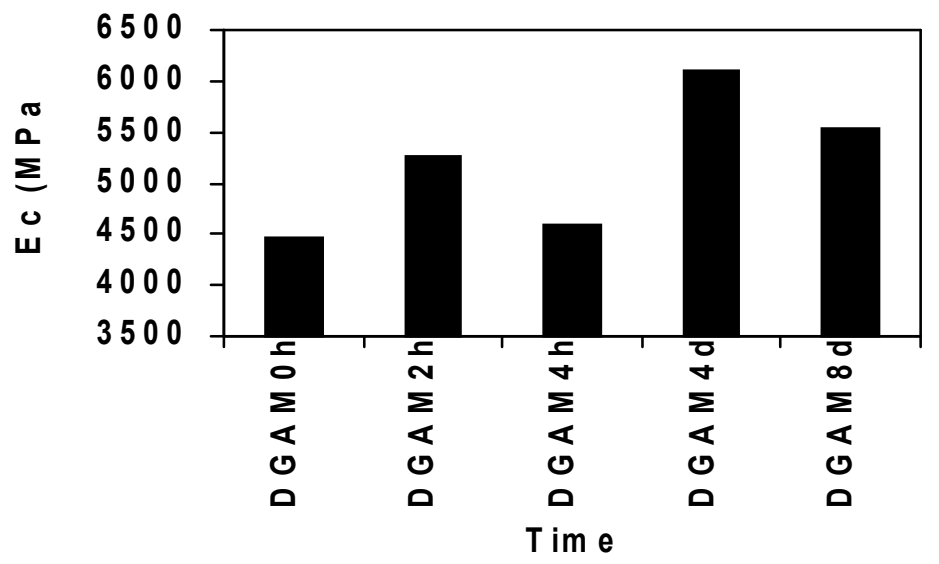

Fig. 8 Modulus of elasticity of DGAMs.

\section{Low temperature property}

It is commonly accepted that at low temperature, bituminous materials exhibit elastic behavior. For an elastic material, the modulus is defined as the ratio of stress/strain. For bituminous materials, this is defined as stiffness modulus [13] which, in the case of flexural testing, is called the flexural stiffness. The flexural stiffness is determined as follows:

$S_{t}=\left[(P x L) /\left(b x d^{2}\right)\right]$

Where:

$\mathrm{St}=$ stiffness modulus

$\mathrm{P}=$ load at break

$\mathrm{L}=$ beam span

$\mathrm{b}=\mathrm{av}$. beam width

$\mathrm{d}=\mathrm{av}$. beam depth.

St is a measure of the stiffness of the material. In addition, another parameter may be determined, namely flexural modulus of the material is determined by: 
$S_{t}=\left[\left(\operatorname{PxL}^{3}\right) /\left(6 \mathrm{xb}^{2} \mathrm{x} \mathrm{d} \mathrm{d}^{2} \mathrm{x} \Delta\right)\right]$

Where:

$\mathrm{Sr}=$ flexural modulus (modulus of rupture)

$\Delta=$ deflection at the beam center; and the other variables as defined above.

The flexural test results of aged DGAMs are given in Figure 9 for 0 and $-10^{\circ} \mathrm{C}$ testing temperatures. They show an increase in both stiffness and modulus of rupture of the mixtures at low temperatures with the variation in aging periods. For a properly designed mixture at low temperature climates, it is desirable to have a high modulus of rupture to ensure adequate tensile strength and at the same time have a low stiffness modulus to avoid being excessively brittle.

From Figure 9, it can be observed that the ranges of the modulus of rupture (MR) for DGAM $_{0 \mathrm{~h}}, \mathrm{DGAM}_{2 \mathrm{~h}}, \mathrm{DGAM}_{4 \mathrm{~h}}, \mathrm{DGAM}_{4 \mathrm{~d}}$, and DGAM $\mathrm{D}_{8 \mathrm{~d}}$ samples are 5160 to $5642 \mathrm{MPa}, 6370$ to $6810 \mathrm{MPa}, 5284$ to $5707 \mathrm{MPa}, 6523$ to $6997 \mathrm{MPa}$, and 6393 to $6804 \mathrm{MPa}$ at 0 and $-10^{\circ} \mathrm{C}$, respectively. For these, COV of results observed were 1.95 to $3.12,1.11$ to $2.1,2.1$ to 2.14 , 1.78 to 2.3 , and 1.92 to $2.05 \%$, respectively. Similarly, average stiffness modulus values obtained for DGAM ${ }_{0 \mathrm{~h}}, \mathrm{DGAM}_{2 \mathrm{~h}}, \mathrm{DGAM}_{4 \mathrm{~h}}, \mathrm{DGAM}_{4 \mathrm{~d}}$, and DGAM $\mathrm{DAd}_{8 \mathrm{~d}}$ are 0.722 to $1.303 \mathrm{MPa}$, 1.21 to $1.732 \mathrm{MPa}, 0.789$ to $1.387 \mathrm{MPa}, 1.45$ to $1.994 \mathrm{MPa}$, and 1.32 to $1.737 \mathrm{MPa}$ at 0 and $10^{\circ} \mathrm{C}$, respectively. From the results, it is evident that aged DGAMs perform better than unaged mixture at low temperature, which is a desirable characteristic of aged DGAMs.
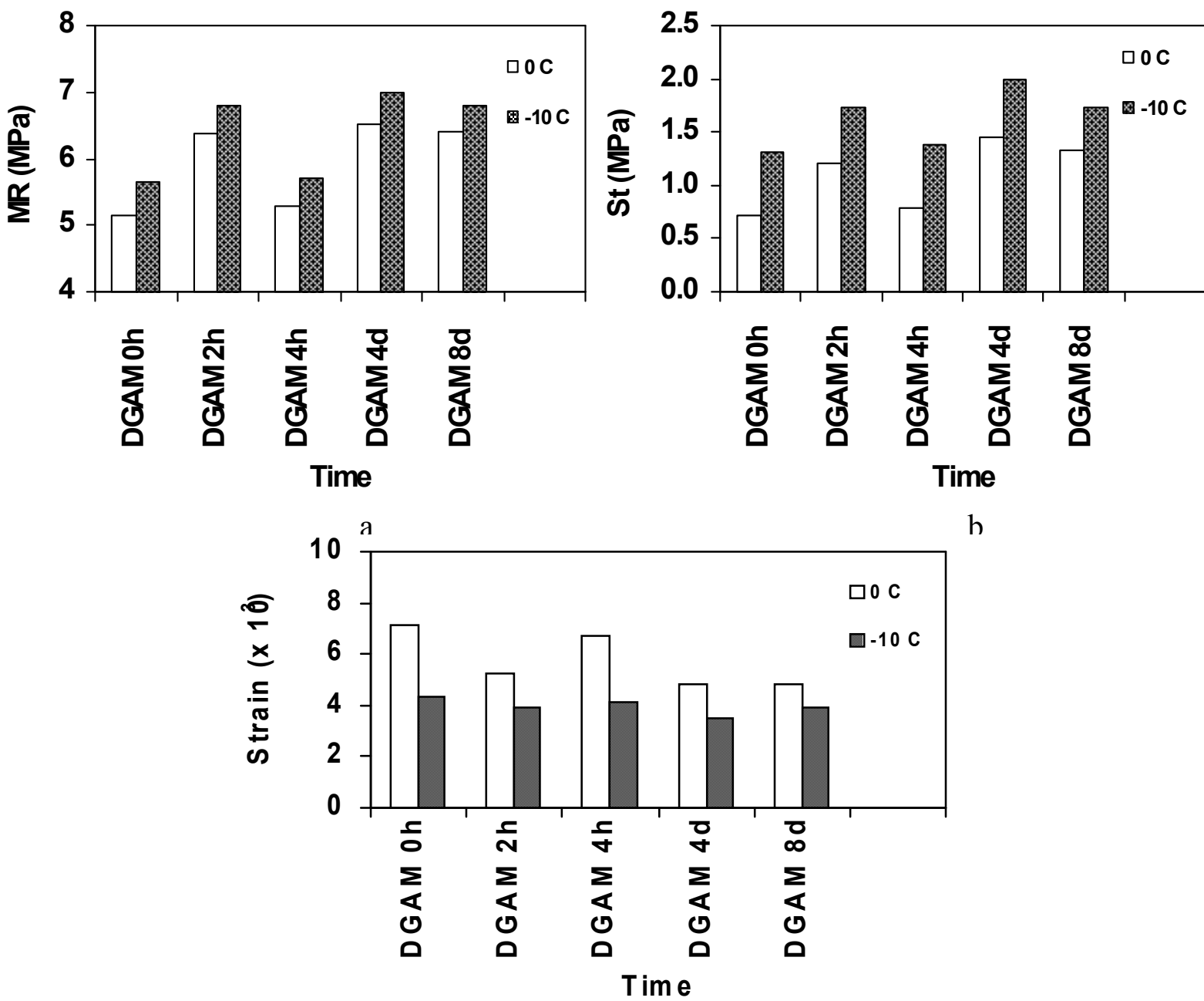

h

Fig. 9 Flexural strength properties of DGAMs (a-Modulus of rupture, b-Stiffness modulus, and c-strain) 


\section{Cohesion test}

Cohesion is the most important test to measure the viscosity of asphalt cement binder. Cohesion of unaged and aged DGAMs was tested at $60 \pm 3^{\circ} \mathrm{C}$ according to ASTM D-1560 [4]. STOA and LTOA DGAMs showed higher cohesion values than unaged DGAMs as shown in Figure 10. Test results indicate that cohesion for $\mathrm{DGAM}_{0 \mathrm{~h}}, \mathrm{DGAM}_{2 \mathrm{~h}}, \mathrm{DGAM}_{4 \mathrm{~h}}$, DGAM $_{4 \mathrm{~d}}$, and DGAM ${ }_{8 \mathrm{~d}}$ samples are $218,302,288,339$ and 314 at $60^{\circ} \mathrm{C}$, respectively, the cohesion of unaged DGAM increases by 39,56 , and $44 \%$ for $2 \mathrm{~h}, 4 \mathrm{~d}$, and $8 \mathrm{~d}$ aging periods, respectively. Therefore, aging has improved the cohesion of DGAMs, which indicates that aging increase the viscosity of virgin asphalt.

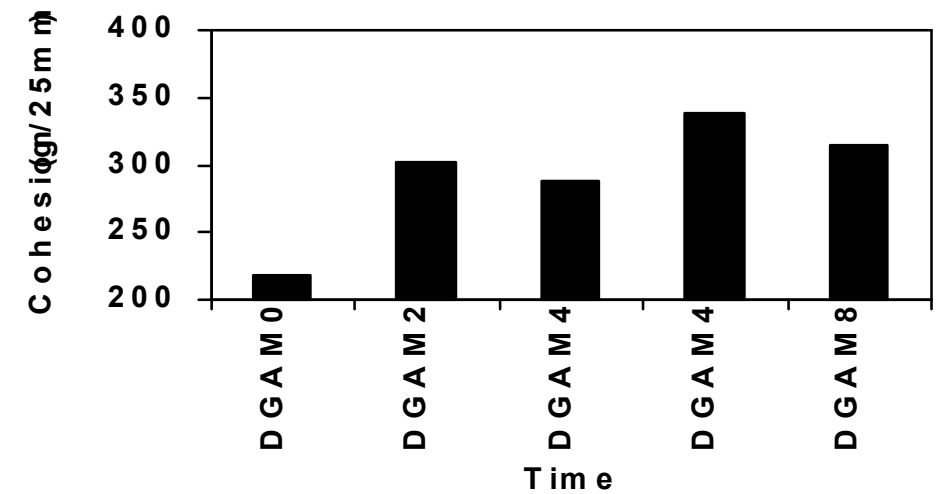

Fig. 10 Cohesion of DGAMs

\section{Aging susceptibility}

Aging susceptibility was measured by aging index using the following equation: Aging Index $=$ (cohesion of aged DGAMs /cohesion of unaged DGAMs). It can be seen from Figure 11 that aging index increases for STOA and LTOA, due to the increasing in bonds between asphalt cement binder and aggregates. Test results indicate that aging index for $\mathrm{DGAM}_{2 \mathrm{~h}}$, $\mathrm{DGAM}_{4 \mathrm{~h}}, \mathrm{DGAM}_{4 \mathrm{~d}}$, and $\mathrm{DGAM}_{8 \mathrm{~d}}$ samples are $1.39,1.32,1.56$, and 1.44 at $60^{\circ} \mathrm{C}$, respectively. These results comply with those obtained by John and David [14].

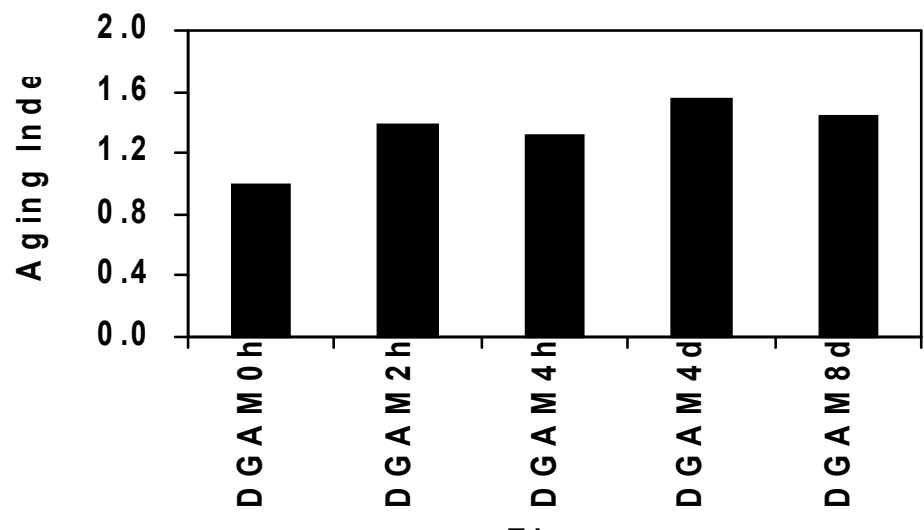

Tim e

Fig. 11 Aging index of DGAMs 


\section{Benefits of aging}

Structural failures in a flexible pavement are of two types, namely surface cracking and rutting. Cracking is due to fatigue caused by repeated application of load in the bounded layer generated by the traffic. Rutting is developed due to accumulation of pavement deformation in various layers along the wheel path. Horizontal tensile strain $\left(\varepsilon_{t}\right)$ developed at the bottom of the bituminous layer or the vertical compressive strains $\left(\varepsilon_{\mathrm{c}}\right)$ developed at the top of the subgrade, respectively, have been considered as indices of fatigue and rutting of the pavement structure. Yang [15] considers a rut depth of $12.7 \mathrm{~mm}$ to be a failure criterion for flexible pavement and the rutting in Eq. (4) is used:

$$
\mathrm{N}_{\mathrm{d}}=1.365 \times 10^{-9}\left(\varepsilon_{\mathrm{c}}\right)^{-4.477}
$$

Where $\mathrm{N}_{\mathrm{d}}=$ number of cumulative standard axles to produce a rutting of $12.7 \mathrm{~mm}$.

The surface deflection $\left(\mathrm{w}_{\mathrm{o}}\right)$ and the horizontal tensile strain at the bottom of binder layer $\left(\varepsilon_{t}\right)$ of unaged and aged pavement system were captured for different thicknesses of the DGAM and base using multi-layer elastic analysis program, BISAR using 40kN set of dual tires with $105 \mathrm{~mm}$ radius. For aged system, thickness of the DGAM of $50 \mathrm{~mm}$, binder layer of $50 \mathrm{~mm}$, and subbase course of $200 \mathrm{~mm}$ were maintained constant and the base course thickness was varied. Similarly, DGAM thickness was varied for a constant binder of $50 \mathrm{~mm}$, base of $200 \mathrm{~mm}$, and subbase of $200 \mathrm{~mm}$.

Figure 12 shows this variation of surface deflection $\left(\mathrm{w}_{\mathrm{o}}\right)$ and the horizontal tensile strain at the bottom of binder layer $\left(\varepsilon_{t}\right)$. These results were used to study the benefits of aging the DGAM in terms of LTR and TBR. The TBR gives the extension in the service life of pavement due to aging and can be written in the equation form as:

$$
\mathrm{TBR}=\mathrm{N}_{\mathrm{dA}} / \mathrm{N}_{\mathrm{dU}}
$$

Where $\mathrm{N}_{\mathrm{d}}=$ number of traffic passes required for producing a pavement surface deformation (rutting) up to the allowable rut depth and expressed in $\mathrm{mm}$; and A and $\mathrm{U}$ denote aged and unaged pavement sections.

Al-Hadidy [16] evaluated the benefits of fiber reinforced SG soil in terms of LTR for the equivalent service life of the pavement. It can be defined as:

$$
\operatorname{LTR}=\left[\left(\mathrm{D}_{\mathrm{U}}-\mathrm{D}_{\mathrm{A}}\right) / \mathrm{D}_{\mathrm{U}}\right] \times 100
$$

$\mathrm{D}_{\mathrm{U}}$ and $\mathrm{D}_{\mathrm{A}}=$ DGAM and base thicknesses of unaged and aged pavement sections.

The results of multi-layer elastic analysis presented in Figure 12 indicate that the horizontal tensile strain at the bottom of binder layer and the vertical compressive strain in the standard pavement section designed with DGAM of $4460 \mathrm{Mpa}$ is $340 \mu$ and $248 \mu$, respectively. For a constant thickness of binder, base and subbase, these strain levels were obtained for pavement section containing $\mathrm{DGAM}_{2 \mathrm{~h}}$ thickness of $46 \mathrm{~mm}$ and $\mathrm{DGAM}_{4 \mathrm{~d}}$ thickness of $43 \mathrm{~mm}$. 


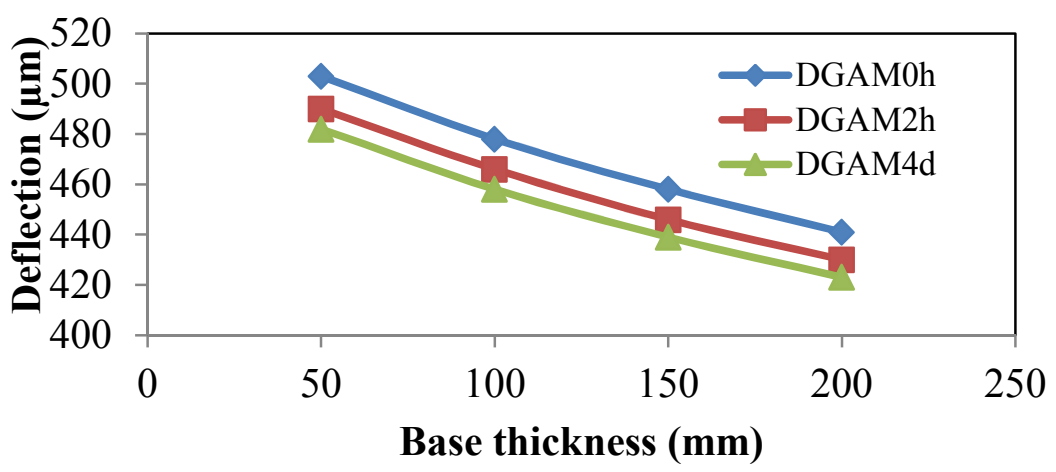

(a)

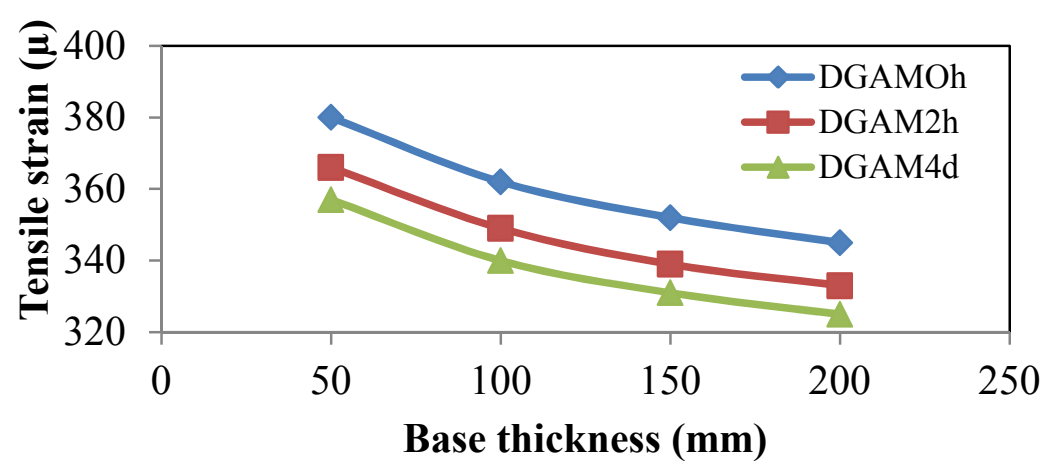

(b)

Fig. 12 Variation of (a- surface deflection, \& b- critical tensile strain) with base thickness

If the pavement section is kept the same for unaged and aged DGAM, the $\varepsilon c$ reduces from $248 \mu$ in the case of unaged to 243 and $239 \mu$ and for DGAM $_{2 \mathrm{~h}}$ and DGAM $_{4 \mathrm{~d}}$, respectively; giving the TBR of 1.1 and 1.2, respectively. It means that aged pavement will have a life 1.1 and 1.2 times that of unaged pavement. These results show that for a constant thickness of DGAM, binder, and sub base these strain levels were obtained for a base thickness of 130 and $90 \mathrm{~mm}$, in the case of $\mathrm{DGAM}_{2 \mathrm{~h}}$ and $\mathrm{DGAM}_{4 \mathrm{~d}}$ pavement section, respectively. From these results, it was found the thickness of DGAM and base layer of unaged pavement section reduces by $8 \%$, and $14 \%$, and 35 and $55 \%$ for $\mathrm{DGAM}_{2 \mathrm{~h}}$ and $\mathrm{DGAM}_{4 \mathrm{~d}}$, respectively, for almost the same service life of aged and unaged pavements. Therefore, the flexible pavement can be designed by adopting any of these alternatives.

The pavement can also be designed for any intermediate thickness to reduce the thickness of the DGAM or base layer as well as to gain additional benefits in terms of extension in service life of the pavement. For example, in the case of $\mathrm{DGAM}_{4 \mathrm{~d}}$, the thickness of the base can be theoretically reduced to less than $90 \mathrm{~mm}$ (55\%LTR) for designed vertical compressive strain of $248 \mu$. In addition, for all alternatives analyzed, it was found that the surface deflection decreases by 2 to $4 \%$. It means that the overall strength of pavement has been increased due to using aged DGAM layer.

\section{CONCLUSIONS}

Based on the testing and analysis the following conclusions may be made:

A) A review of the Marshall, indirect tensile strength, compressive strength, flexural strength, cohesion, and water sensitivity results indicated the following: 
1. Marshall results indicated that the MQ value of unaged DGMA increased by $56 \%$, $17 \%, 111 \%$, and $78 \%$ at $2 \mathrm{~h}, 4 \mathrm{~h}, 4 \mathrm{~d}$, and $8 \mathrm{~d}$ aging periods, respectively. It can be said that the aged DGAMs provide better resistance against permanent deformations due to their high stability and high MQ and indicate that aged DGAMs could be use in military airfield pavements where stiff asphalt mixture and low asphalt content are required.

2. Unconditioned mixture tensile strength increases 17,14 , and $10 \%$ at $2 \mathrm{~h}, 4 \mathrm{~d}$ and $8 \mathrm{~d}$ aging periods.

3. The percentage increase in compressive strength value for unaged DGAM subjected to $2 \mathrm{~h}, 4 \mathrm{~d}$ and $8 \mathrm{~d}$ aging periods was found to be 20 and $26 \%, 13$ and $28 \%$, and 22 and $36 \%$ at 25 and $60^{\circ} \mathrm{C}$, respectively.

4. It was found that the IRS of the unaged DGAM increases by $6 \%, 11 \%, 13 \%$ and $11 \%$ for $\mathrm{DGAM}_{2 \mathrm{~h}}, \mathrm{DGAM}_{4 \mathrm{~h}}, \mathrm{DGAM}_{4 \mathrm{~d}}$, and $\mathrm{DGAM}_{8 \mathrm{~d}}$, respectively

5. The tensile strength ratio for $\mathrm{DGAM}_{0 \mathrm{~h}}, \mathrm{DGAM}_{2 \mathrm{~h}}, \mathrm{DGAM}_{4 \mathrm{~h}}, \mathrm{DGAM}_{4 \mathrm{~d}}$, and $\mathrm{DGAM}_{8 \mathrm{~d}}$ was found to be $90,82,76,94$, and $93 \%$, respectively. This indicates that aging does not cause the mixture to weaken when exposed to moisture.

6. The modulus of elasticity at $25^{\circ} \mathrm{C}$ temperatures increases by $18 \%, 37 \%$ and $24 \%$ for 2 $\mathrm{h}, 4 \mathrm{~d}$, and $8 \mathrm{~d}$ aging periods, respectively.

7. The modulus of rupture value for unaged DGAM subjected to $2 \mathrm{~h}, 4 \mathrm{~d}$ and $8 \mathrm{~d}$ aging periods was found to be 23 and $21 \%, 26$ and $24 \%$, and 24 and $21 \%$ at 0 and $-10^{\circ} \mathrm{C}$, respectively. From the results, it is evident that aged DGAMs perform better than unaged mixture at low temperature, which is a desirable characteristic of aged DGAMs.

8. The cohesion of unaged DGAM increases by 39,56 and $44 \%$ for $2 \mathrm{~h}, 4 \mathrm{~d}$, and $8 \mathrm{~d}$ aging periods, respectively. Therefore, aging has improved the cohesion of DGAMs, which indicates that aging increase the viscosity of virgin asphalt.

9. It was found that aging index for DGAM increases by $39,32,56$, and $44 \%$ for $2 \mathrm{~h}$, $4 \mathrm{~h}$, $4 \mathrm{~d}$, and $8 \mathrm{~d}$ aging periods, respectively. These results comply with those obtained by John and David [14]

10. Statistical relationships between the DGAMs performance tests are developed for situations in which: a) the indirect tensile and/or compressive strength tests are not available, and /or b) the designer does not choose to use those tests.

11. Based on the observations and the analysis of the results using a statistical program; indirect tensile strength test is the most promising of stripping when applied to airfield and highway paving mixtures.

12. From SPSS statistical analysis program, an optimization table based on the performance measures conducted on DGAMs is prepared. Results obtained from such analysis can be used to select the aging conditions for any field applications. Actual selecting would depend upon the option exercised by the designer.

13. The aging was performed above $5 \mathrm{~h}$ and at $85^{\circ} \mathrm{C}$, called "long term aging" which simulates the aging of the asphalt binder through the pressure-aging vessel (PAV); and

14. Results indicated that flexible pavement with high performance, durability and more economic can be obtained with STOA and LTOA conditions of $154^{\circ} \mathrm{C}$ for $2 \mathrm{~h}$, and 85 ${ }^{\circ} \mathrm{C}$ for $4 \mathrm{~d}$, respectively.

B) Mechanistic-empirical design approach results indicated the following: 
1. If the pavement section is kept the same for unaged and aged DGAM, the pavement gives TBR value of 1.1 and 1.2 for $2 \mathrm{~h}$ and $4 \mathrm{~d}$ aging periods respectively.

2. It was found the thickness of DGAM and base layer of unaged pavement section reduces by $8 \%$, and $14 \%$, and 35 and $55 \%$ for $\mathrm{DGAM}_{2 \mathrm{~h}}$ and $\mathrm{DGAM}_{4 \mathrm{~d}}$, respectively, for almost the same service life of aged and unaged pavements.

3. The pavement consisting of aged DGAM as a surface layer is beneficial in reducing the construction materials. Actual savings would depend upon the option exercised by the designer for reducing the thickness of an individual layer.

4. The obtained results in this study may vary if bitumen from other sources is used.

\section{REFERENCES}

[1] Soon-Jae Lee, Serji N. Amirkhanian, \& Kwang W. Kim (2009), "Laboratory Evaluation of the Effect of Short-Term Oven Aging on Asphalt Binders in Asphalt Mixtures Using HP-GPC", Construction And Building Material.

[2] Al-Hadidy and Tan Yi-Qiu., (2007) "Long-Term Aging of Polypropylene Asphalt Paving Mixtures", Proceeding of the 26th Southern African Transport Conference (SATC 2007), 9-12 July 2007. P761-767. ISNB Number: 1-920-01702-X Pretoria, Accepted as a Word Cup 2010 Traffic Simulation.

[3] Soon-Jae Lee A, Serji N. Amirkhanian, Khaldoun Shatanawi , Kwang W. Kim , (2007) "Short-Term Aging Characterization of Asphalt Binders Using Gel Permeation Chromatography and Selected Superpave Binder Tests", Science Direct, Construction and Building Materials.

[4] American Society for Testing and Materials (ASTM), (2004), Standard Specification, Section 4, Vol. 04-03.

[5] Masson J-F, Pelletier L., \& Collins P., (2001), "Rapid FTIR Method for StyreneButadiene Type Copolymers In Bitumen".

[6] Asphalt Institute (1984). "Mix design method for asphalt concrete and other hot-mix types" (MS-2).

[7] Asphalt Institute (2002). "Superior performing asphalt pavement". Mix design series, No. 2, (SP-2).

[8] AASHTO Designation: R30, America Association of State Highway and Transportation Officials, Washington, D.C. Practice for Short and Long Term Aging of Hot Mix Asphalt (HMA), 2002.

[9] Bell A. Chris, Alan J. Wieder, \& Marco J. Fellin. , (1994) " Laboratory Aging of Asphalt-Aggregate Mixtures: Field Validation", SHRP-A-390, Strategic Highway Research Program, Oregon State University, National Research Council, Washington, D.C.

[10] State cooperation of road and bridges, (2003). "Hot mix asphaltic concrete pavement", Iraqi standard specification, Ministry of Housing and Construction. Department of Design and Study, Section R-9.

[11] Bradley, J. Putman, and Serji, N. Amirkhanian. (2004) "Utilization of waste fibers in stone matrix asphalt mixtures". J. Resources Conservation and Recycling. (42):265-274.

[12] Nancy L.Leech et.al. (2005) " SPSS for Intermediate statistics : Use and Interpretation", Lawrence Erlbaum Associates, Inc., Publishers, 10 Industrial Avenue, Mahwah, New Jersey 07430. 
[13] Busby EQ. and Rader LF. (1972) "Flexural stiffness properties of asphalt concrete at Low temperatures.” Proceedings, AAPT, Vol.41:163-187.

[14] John, R., David, W., (2003) “The Shell Bitumen Hand Book".5th Ed., Thomas Telford Ltd., pp.157-163,213,214.

[15] Yang H.H, (2012), "Pavement Analysis and Design", Prentice-Hall, Inc., A Paramount Communications Company, Englewood Cliffs, New Jersey 07632, USA: 57, [16] Al-Hadidy A.I., (2009), "Characterization of Polymer Modified Road Building Materials: Laboratory and Field Evaluation". Ph.D. dissertation, School of Transportation and communication, Harbin Institute of Technology, China. 